M. Fg. Scott, J. D. MacArthur and D. M. G. Newbery, Project Appraisal in Practice, Heinemann Educational Books, 1976, $\$ 9.50$.

\title{
John Weiss
}

This is an important book for those working in the field of project appraisal. The authors have produced estimates of shadow prices and discussions of their application to particular projects, which are the most detailed and comprehensive yet to be published.

The book is divided into three parts. Part $I$ is concerned with deriving a set of shadow prices for Kenya. The analysis is set within the Little-Mirrlees framework, using uncommitted income in the hands of the government measured in world prices as numeraire; however the procedure to derive a comprehensive set of shadow prices for a large number of goods is original. A number of primary inputs are identified and their shadow prices estimated; a form of input-output analysis is then used to establish the direct and indirect primary input content for 
approximately 130 items. The shadow prices for these items are therefore the sum of the shadow price values of the primary inputs used in their production. Part I gives a detailed discussion of the valuation of the primary inputs such as wages, non-wage incomes, certain non-traded items and foreign exchange: Parts II and III of the book are agricultural case studies; Part II is an appraisal at shadow prices of some of the settlement schemes introduced in Kenya during the 1960s; Part III analyses a scheme for intensive cattle feeding in Kenya.

Whilst the two case studies have a general interest for those involved in agricultural planning, the major objectives of the book as a whole are to show how the Little-Mirrlees method of social cost-benefit analysis can be applied in practice, and to suggest improvements in the light of the experience gained from this practical application. The intended audience are primarily professional economists concerned with project appraisal and the reader not already conversant with the literature in this area will find some of the theoretical explanations in Part I complex and difficult; this is particularly true of the discussion of income distribution weights. However, the project analysis practitioner will find many useful insights.

The exposition is helped considerably by the use of summary chapters which introduce each of the three parts of the book. The first chapter is particularly helpful in that it gives suggestions for short-cuts in estimating shadow prices; these short-cuts are suggested by the results of the detailed analysis. For example, in the valuation of non-traded goods in Kenya the use of a single conversion factor of 0.8 would produce only a small error in comparison with the use of the full set of 28 conversion factors for non-traded items. As is pointed out, however, the problem is that without a great deal of initial data one may not arrive at a correct crude estimate.

Many detailed problems which arise in the practical application of social cost-benefit analysis, but which receive relatively little attention in the literature, are examined. Examples of these in Part I are the treatment of the transport cost element in the valuation of traded goods, and how this can be significant for many traded items; the social valuaion of labour which is drawn from many different occupations (for certain types of workers the cost of transfer between nine different occupations is considered); the treatment of differences between rural and urban prices for consumption goods (on average it was found that urban prices were 60 per cent higher); and the valuation in terms of world prices of goods which are consumed locally and are non-tradeable internationally.

In Part II there is an interesting discussion of the social valuation of land based on an estimate of its social opportunity cost in terms of world prices; similarly Part III contains a detailed analysis of the valuation of cattle in terms of an equivalent world market price.

The reader is shown an ingenious set of solutions to many complicated problems; the analysis is a major and compelling reply to those who criticise social cost-benefit analysis for its inability to cope with many of the difficulties which arise in project appraisals. However, it should not be thought that all problems have been resolved. The authors have demonstrated the solution to some, but in various places in the text acknowledge the existence of others. A brief list of some of the important areas where social cost-benefit analysis still treads on shaky ground makes the point:

-In the area of income distribution weighting, the analysis rests upon an identification of a critical income level, and a value for the elasticity of the marginal utility of income. It is clearly difficult to obtain agreed values for these parameters, and in the absence of agreement any set of income weights will be open to challenge. The analysis in the study illustrates clearly the problems involved: the critical income level had to be based on minimum income targets set by the 1972 International Labour Organisation mission to Kenya; the value for the elasticity parameter was simply arbitrary; and even data on existing income distribution had to be compiled from varying and unreliable sources.

- Some commodities show substantial variations in their shadow prices over time. Estimation of a future shadow price is, therefore, a forecasting problem, which is similar conceptually whether the appraisal is at shadow or at market prices. Nonetheless fluctuations in prices, particularly world market prices, make realistic forecasts very difficult. The treatment of maize in the present study illustrates this point.

-Where there are large numbers of non-traded goods in an economy, calculation of their value in terms of world prices becomes very difficult. Input-output tables are a possible source of data; however, often they identify inputs at too great a level of aggregation, and in many cases are years out of date. The Kenya study did not have an input-output table to use, and relied on detailed survey data and cost studies to identify the cost structure of non-traded items. This approach requires both time and a considerable amount of very detailed information; the more non-traded 
items in the economy there are, the more difficult this procedure will be.

-The discount rate used in social cost-benefit analysis, although a key parameter, is of ten highly uncertain. Estimation of the return on the marginal public sector project in world price terms is clearly difficult. The discussion of the accounting rate of interest is one of the weakest sections of the Kenya study. The reasons for selecting 10 per cent as a best guess are not very substantial.

-Finally, social cost-benefit analysis cannot cope easily with what may be termed dynamic secondary effects. An example of these effects is where additional demand for non-traded goods generates new savings which supply the investment required for the production of these goods. In this case of the generation of additional savings, the social costs of producing the non-tradeables will be considerably lower than where investment is switched from other activities. The shadow prices of the goods will therefore be lower. This problem is raised in the book to suggest an area for further research.

In conclusion it must be stressed that not only have the authors given valuable guidance regarding the calculation and application of shadow prices, but have also both explicitly and implicitly identified further problem areas in the application of social cost-benefit analysis. 